DOI 10.18551/rjoas.2019-11.20

\title{
FORECASTING SOLID MEDICAL WASTE DEMAND USING EXTRAPOLATIVE DAILY DATA SETS: A CASE STUDY OF A MEDICAL SOLID WASTE PROCESSING SERVICE PROVIDER IN INDONESIA
}

\author{
Gumilar Ricky*, Maulina Erna, Arifianti Ria \\ Postgraduate Program of Business Administration, Faculty of Social and Politic Science, \\ University of Padjadjaran, Bandung, Indonesia \\ *E-mail: ricky15002@mail.unpad.ac.id
}

\begin{abstract}
Due to a service provider for collecting and incinerating of solid medical waste failed to fulfill the requirements of the Indonesian Ministry of Environment regarding the difficulties to predict the amount of medical solid waste in the primary and secondary source. This research was to study the most optimal time series model of demand forecast for service provider for solid medical waste incineration. In this study, the use of extensive records from past data required due to the need intensive supervision to handle infection risk and over demand that may happen every day. The forecasting methods analyzed included: moving average, weighted moving average, exponential smoothing, and exponential smoothing with trend adjustment. The optimal forecasting model was measured using Mean Absolute Deviation (MAD), Mean Square Error (MSE), and Mean Absolute Percent Error (MAPE). The result showed that exponential smoothing which assumed stable fluctuation of the actual value $(\alpha=0.10)$ is the most optimal forecast model based on the values of MAD and MAPE. Meanwhile, based on MSE showed that MA $(n=7)$ was the most optimal forecasting model. The difference in optimal forecasting measurement models guide discretion to choose the right forecasting model based on optimal forecasting model interpretation.
\end{abstract}

\section{KEY WORDS}

Solid medical waste, demand forecasting, forecasting, moving average, weighted moving average, exponential smoothing.

To avoid risks and health problems, solid medical waste processing by the incineration method is the most popular method. Incineration method not only more practical, effective, and reduce cost, but also cheaper than other methods (Ministry of Environment, 2014). However, incineration should meet the design criteria of incineration technology to make it more environmentally friendly. That's why health care facilities prefer to offer incinerating medical solid waste liability to service provider for medical solid waste incineration. Instead of solving the problem of solid medical waste, service provider for collection and incineration face the problem of excess orders due to the low awareness of health service facilities to sort their waste. Hence, solid medical waste service providers for collection and incineration have to anticipate the possibility of a surge in demand from their customers.

Service provider for collecting and incinerating of solid medical waste faces the problem of demand uncertainty and lack of information about the hospital's medical waste management system. Surely, a service provider for collecting and incinerating has no authority to control hospital behavior to reduce the hospital's solid medical waste. A data system for medical waste generation and management is one of the hardest to create and organize (Karpušenkaitè et al., 2016). Although the demand for medical solid waste incineration services is difficult to predict the future, demand forecasting can provide direction for managers who need information about future demand (Heizer et al., 2017). Forecasting that involves expanding data daily is needed to provide information about the daily demand fluctuations and to fulfill regulations of medical solid waste treatment.

We have collected data from a service provider for incineration medical solid waste in West Java, Indonesia. During the period from May to August 2017, based on these data it is known that there were 45 days of over demand, which caused solid medical waste to be 
stacked carelessly and impacted the administrative sanctions imposed by the Ministry of Environment and Forestry. Hence, we have mapped the papers on the topic of demand forecasting which may be applied to solid medical waste incineration services companies or service provider for solid medical waste collection and treatment due to inefficient waste sorting from the source. Only a few research papers can be applied to service provider for waste collection and treatment or incineration. This paper only overviews those research papers that may support to predict solid medical waste generation in the future based on papers that have mapped.

Some researchers have been analyzed correlation between the number of beds and health care waste generation rates (Maamari et al., 2014; Komilis et al., 2012). Other researchers using sophisticated method to forecast amount of solid medical waste generation by analyzing several prediction (Gusca et al., 2015; Jahandideh et al.,2009; AlKhatib, 2016; Karpušenkaite et al., 2016), or to predict quantities of hospital waste components and asses the cost of treatment (Eleyan et al, 2013). These researches are relevant to predict of the amount of solid medical waste generation produced in the stage of storage, transportation, and disposal of hospital waste but not for service provider for collection and treatment or incineration of solid medical waste. Moreover, it is clear that the problem of the generation rate of solid medical waste is caused by lack of hospital waste management (Chaerul, et al, 2007; Daou et al., 2015; Bokhoree, et al., 2013). Therefore, we developed some time series forecasting models regarding the generation of medical solid waste generation by Karpusenkaite (2016).

Since the need for accurate, simple, and time-saving forecasting methods is highly recommended (Ryu \& Sanchez, 2003), this research aims to examine the most optimal forecast future demand for the collection and treatment of solid medical waste by time series method to decompose the elements in the series of demand records. The use of time series method on the assumption that the future values are predicted only from past values and other variables, no matter how potentially valuable, may be ignored (Heizer, et al, 20117). Moving average (SMA) and simple exponential smoothing (SES) forecasting models is the most widely used based on the usage, familiarity, and satisfaction (Ali \& Boylan, 2011). In addition, this study compares the forecasting performance of weighted moving average, and exponential smoothing with trend adjustment. Furthermore, we compare the optimization based on its accuracy value.

\section{METHODS OF RESEARCH}

In connection with the characteristic of medical solid waste that must be incinerated every day, then the demand forecasting of medical solid waste processing services in this study involves daily actual from customers of health care service provider for collection and treatment.

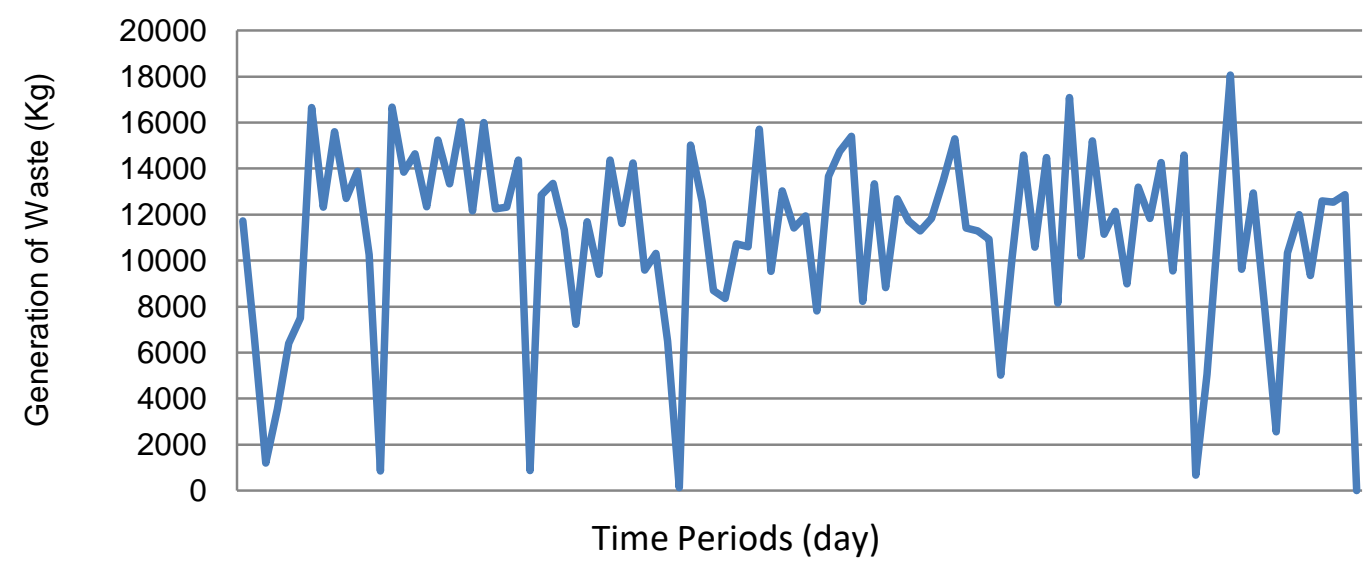

Figure 1 - Observed Actual Value of Demand for Medical Solid Waste Collection and Treatment 
The daily actual data of medical solid waste demand collected from a service provider for incineration of health care waste as primary sources in West Java, Indonesia. The samples collected were the demand period of 106 days from May 1, 2017 to August 14, 2017. There are 9 days of actual data that show no actual demand at all, so we categorized them into irregular variations and we removed from the data. Irregular variations are due to unusual circumstances and should be removed from the data (Stevenson, 2015).

The data analysis in this study is carried out with the following models.

A moving average forecast uses a number of historical actual data values to generate a forecast (Heizer et al. 2016). Moving average equation is as follows:

$$
M A=\frac{\Sigma \text { demand in the previous period } n}{n}
$$

The total number of days on moving average $(n)$ is determined $2,3,4,5,6$, and 7 .

To make forecasting techniques more responsive to changes because more recent periods, weights are used to place more emphasis on recent value (Heiser et al., 2016). Weighted moving average equation is as follows:

$$
W M A=\frac{\Sigma(\text { Weight of period } n)(\text { Demand on period } n)}{\Sigma W \text { eight }}
$$

The total demand in the period of data observed was divided into 6 groups, these are, 2 days, 3 , days, 4 days, 5 days, 6 days, and 7 days. The weights for each period group are determined by trial and error. The total weight set in this study is no more than 1.00 (Stevenson, 2015). Based on the results of trial and error, the weight values in this study are set as follows:

Table 1 - Giving Weight on Period ( $\mathrm{n}$ )

\begin{tabular}{|c|c|c|c|c|c|c|c|}
\hline $\begin{array}{c}\text { Weight on } \\
\text { Day-1 }\end{array}$ & $\begin{array}{c}\text { Weight on } \\
\text { Day-2 }\end{array}$ & $\begin{array}{c}\text { Weight on } \\
\text { Day-3 }\end{array}$ & $\begin{array}{c}\text { Weight on } \\
\text { Day-4 }\end{array}$ & $\begin{array}{c}\text { Weight on } \\
\text { Day-5 }\end{array}$ & $\begin{array}{c}\text { Weight on } \\
\text { Day-6 }\end{array}$ & $\begin{array}{c}\text { Weight on } \\
\text { Day-7 }\end{array}$ & Total Weight \\
\hline 0.70 & 0.30 & - & - & - & - & - & 1.00 \\
\hline 0.50 & 0.35 & 0.15 & - & - & - & - & 1.00 \\
\hline 0.45 & 0.25 & 0.20 & 0.10 & - & - & - & 1.00 \\
\hline 0.30 & 0.25 & 0.20 & 0.15 & 0.10 & - & - & 1.00 \\
\hline 0.24 & 0.21 & 0.18 & 0.15 & 0.12 & 0.10 & - & 1.00 \\
\hline 0.22 & 0.19 & 0.17 & 0.14 & 0.12 & 0.09 & 0.07 & 1.00 \\
\hline
\end{tabular}

Exponential smoothing is a weighted-moving-average forecasting technique in which data points are weighted for average by an exponential function (Heizer et al. 2016). Exponential smoothing equation is as follows:

$$
F_{t}=F_{t-1}+\alpha\left(A_{t-1}-F_{t-1}\right)
$$

Where: $F_{t}=$ new forecasting; $F_{t-1}=$ previous forecasting period; $A=$ weight $(0 \leq \alpha \leq 1)$; $A_{t-1}=$ previous period of actual demand.

In this research the demand value of the previous period, to start the calculation is determined according to the actual value in the first period (Ostertagova \& Ostergag, 2012). The constant smoothing value $(\alpha)$ is carried out by trial and error with a constant value starting from $\alpha=0,10$ to $\alpha=0.90$ with a distance of 0.10 . The actual demand value, to start the calculation is the actual demand that starts on the first day. Exponential smoothing with trend adjustment is estimated for both the average and the trend are smoothed (Heizer et al. 2016). This analysis modifies the exponential smoothing forecasting method by taking trends into account. Exponential smoothing with trend adjustment equation is as follows:

$$
\begin{gathered}
F_{t}=\alpha\left(A_{t-1}\right)+(1-\alpha)\left(F_{t-1}+T_{t-1}\right) \\
T t=\beta\left(F_{t}-F_{t-1}\right)+(1-\beta) T_{t-1} \\
F I T_{t}=F_{T}+T_{T}
\end{gathered}
$$


Where: $F_{t}=$ exponentially smoothed forecast average of the data series in period $t$; $T_{t}=$ exponentially smoothed trend in period $t ; A_{t}=$ actual demand in period $t ; \alpha=$ smoothing constant for the average $(0<a<1) ; \beta=$ smoothing constant for the trend $(0<b<1)$.

The average constant value for the average $(\alpha)$ and constant value for the trend $(\beta)$ determined of trial and error which starts from $\alpha=0.90$ to $\alpha=0.10$ with an increase of 0.10 on each calculation. The initial values for the smoothed series and the trend must be set in order to start the forecasts. In this research, the first estimated exponentially smoothed forecast average was equal to the first observed data. The first estimated trend was to equal zero (Ryu \& Sanchez, 2003).

Data analysis is carried out by measuring the most optimal forecasting model using Mean Absolute Deviation (MAD), Mean Squared Error (MSE), and Mean Absolute Percent Error (MAPE). These measures are the most popular measures to compare different forecasting models, as well as to monitor forecast to ensure they are performing well (Heizer et al., 2017).

MAD is computed by taking the sum of the absolute values of the individual forecast error by dividing by the number of periode of data (Heizer et al., 2017). MAD equation is as follows:

$$
M A D=\frac{\sum \mid \text { actual }- \text { forecast } \mid}{n}
$$

MAD provides measures the average deviation of the observation from their mean. If the observations are spread out, they will tend to be far from the mean, both above and below (Makridakis et al., 1998).

MSE is the average of the squared differences between the forecasted and observed values (Heizer et al., 2017). MAD equation is as follows:

$$
M S E=\frac{\sum \mid \text { Error forecast }\left.\right|^{2}}{n}
$$

MSE taking errors made positive by squaring each error, then squared errors are average. MSE indicates that we prefer to have several deviations rather than even one large deviation (Makridakis et al., 1998; Heizer et al., 2017).

MAPE is the average of the absolute difference between the forecasted and actual values, expressed as a percentage of the actual values (Heizer et al., 2017). MAPE equation is as follows:

$$
\text { MAPE }=\frac{\sum_{i-1}^{n} 100 \mid \text { Actual }_{i}-\text { forecast }_{i} \mid / \text { Actual }_{i}}{n}
$$

MAPE is one of the most popular measures of the forecast accuracy, although there are several disadvantages, this measurement is the preferred method of business forecasters and practitioners (Kim and Kim, 2016),

The comparisons of the most optimal forecasting model are carried out by creating the ranking based on the lowest forecasting error number. This comparison is made to select the forecasting model that will be applied. The selection of a forecasting model should consider the cost aspect to quickly anticipate the changing demand for medical solid waste processing services. However, the cost aspects and the ability of decision makers to use the function of forecasting are not examined in this study; hence the selection of forecasting is solely observed based on the level of optimality.

\section{RESULTS AND DISCUSSION}

Based on data collection, the following results are demand forecasting with daily data calculated by moving average, weighted moving average, exponential smoothing, and exponential smoothing with trend adjustment. 
Moving Average. Appendix A shows that 7 days observation of actual values included in the moving average, the smoother the resulting trend and random variation than 2 days. Increasing number of observation of actual values tends to smooth out fluctuation and easily to obtain general information of fluctuation. However, the greater the number of actual data that we calculated the more lost information about fluctuation that we can get.

Moving average is computed by dropping the oldest observation and including the newest observation. Hence, extensive data engagement that calculates actual daily values causes this model not to work well when time series contains seasonality. Moving average will always stay within past levels and will not predict changes to either higher or lower levels (Heizer et al., 2017).

In this moving average, determining how many actual data to include in each average refers to how optimal the number of actual data observed to forecast future. The result of the forecasting optimality measurement on moving average is as follows.

Table 2 - Forecasting Optimality Measurement of Average Moving Model

\begin{tabular}{|c|c|c|c|}
\hline $\mathrm{n} / \mathrm{n}$ & MAD & MSE & MAPE \\
\hline $\mathrm{n}=2$ & $3,364.66$ & $20,125,733.76$ & $146.71 \%$ \\
\hline $\mathrm{n}=3$ & $3,389.11$ & $19,356,186.09$ & $146.15 \%$ \\
\hline $\mathrm{n}=4$ & $3,132.44$ & $18,227,192.67$ & $157.24 \%$ \\
\hline $\mathrm{n}=5$ & $3,168.84$ & $18,216,490.51$ & $160.79 \%$ \\
\hline $\mathrm{n}=6$ & $3,003.77$ & $17,106,838.99$ & $165.91 \%$ \\
\hline
\end{tabular}

Table 2 shows several performance of moving average with different $n$ values. Moving average with $n=7$ is a most optimal based on MAD and MSE, however, based on MAPE indicates that moving average with $n=3$ is the most optimal.

Weighted Moving Average. Appendix B shows that weighted moving average with $n=$ 7 smoother the resulting trend and random variation than $n=2$. Both moving average and weighted moving average show relatively similar result, namely increasing number of observation of actual values tends to smooth out fluctuation and easily to obtain general information of fluctuation.

Just like moving average, determining how many actual data $(n)$ to include in each average refers to how optimal the number of actual data observed to forecast future. By adding some weight in this model, make forecasting little responsive to the newest change but this change is affected also by the choice of weights that somewhat arbitrary as there is no formula to determine them. The result of the forecasting optimality measurement on moving average is as follows.

Table 3 - Forecasting Error Measurement of Weighted Moving Average Forecasting Model

\begin{tabular}{|c|c|c|c|}
\hline $\mathrm{n} / \mathrm{n}$ & MAD & MSE & MAPE \\
\hline $\mathrm{n}=2$ & $3,481.01$ & $21,101,090.23$ & $141.54 \%$ \\
\hline $\mathrm{n}=3$ & $3,324.11$ & $19,126,488.93$ & $140.99 \%$ \\
\hline $\mathrm{n}=4$ & $3,252.78$ & $18,558,393.28$ & $146.64 \%$ \\
\hline $\mathrm{n}=5$ & $3,156.83$ & $17,941,899.67$ & $154.53 \%$ \\
\hline $\mathrm{n}=6$ & $3,049.32$ & $17,169,376.12$ & $160.49 \%$ \\
\hline $\mathrm{n}=7$ & $2,981.56$ & $15,801,956.66$ & $160.46 \%$ \\
\hline
\end{tabular}

Table 3 shows several performance of weighted moving average with different $n$ values. Weighted moving average with $n=7$ is a most optimal based on MAD and MSE, however, based on MAPE indicates that moving average with $n=3$ is the most optimal.

Exponential smoothing. Appendix $C$ shows how weight or smoothing constant $(\alpha)$ works smoothest fluctuations. A weight given to average refers to the assumption of average change. Lower $\alpha$ means average fairly stable, and greater $\alpha$ means average is likely to change. This research results show that actual data must be assumed to be stable as low value $(\alpha=0.10$ and $\alpha=0.20)$ to smooth fluctuation. Determining the greater weight causing forecasting value to be more responsive to the previous actual data and a high level of $\alpha$ 
(closely to 1.00) causing forecasting value is getting close value to a previous actual value. Exponential smoothing result show horizon just one period ahead. In this research, the extended data into days assumed that forecast function is no trend, season or random variation but makes this model can be applied for short data. This model reduces any storage data problem, because it doesn't need to store all the historical data.

Since the weight is determined in arbitrary ways, this research relies solely on the result of optimality measurements. The result of the forecasting optimality measurement on exponential smoothing is as follows.

Table 4 - Forecasting Error Measurement of Exponential Smoothing Forecasting Model

\begin{tabular}{|c|c|c|c|}
\hline$\alpha$ & MAD & MSE & MAPE \\
\hline 0.90 & $3,810.78$ & $24,249,858.29$ & $183.24 \%$ \\
\hline 0.80 & $3,625.29$ & $22,393,138.06$ & $170.67 \%$ \\
\hline 0.70 & $3,490.84$ & $20,900,649.92$ & $157.64 \%$ \\
\hline 0.60 & $3,379.19$ & $19,682,953.66$ & $146.71 \%$ \\
\hline 0.50 & $3,291.74$ & $18,668,524.57$ & $136.96 \%$ \\
\hline 0.40 & $3,191.75$ & $17,797,965.87$ & $126.08 \%$ \\
\hline 0.30 & $3,083.49$ & $17,026,025.94$ & $114.28 \%$ \\
\hline 0.20 & $3,010.56$ & $16,332,627.74$ & $102.85 \%$ \\
\hline 0.10 & $2,947.76$ & $15,700,883.86$ & $90.99 \%$ \\
\hline
\end{tabular}

Table 4 shows several performance of exponential smoothing with different a values. Lowest $\alpha$ value is the most optimal performance. It does not look like two previous forecasting, all the optimal measurement (MAD, MSE, and MAPE) shows that moving average with $\alpha=0.10$ is the most optimal weight for exponential smoothing.

Exponential Smoothing with Trend Adjustment. Appendix D, show performance of smoothing constant $(\alpha)$ and smoothing trend $(\beta)$ to smoothing fluctuations. This model assuming the average contains a linear trend. This research shows the result of 81 times trial of different combination $\alpha$ and $\beta$ values. The interesting that we found in these result are 35 result show how forecasting are too warped especially in a greater value of $\beta$. The result of the forecasting optimality measurement on exponential smoothing with trend adjustment is as follows.

Table 7 shows several performance of exponential smoothing with trend with different $\alpha$ values and $\beta$ values. Exponential smoothing with trend adjustment with $\alpha=0.10$ and $\beta=0,20$ is a most optimal combination based on MAD and MSE, however, based on MAPE indicates that $\alpha=0.80$ and $\beta=0,70$ is a most optimal combination.

Table 5 - Mean Absolute Deviation (MAD)

\begin{tabular}{|c|c|c|c|c|c|c|c|c|c|}
\hline MAD & \multicolumn{9}{|c|}{ Weighted Average $(\alpha)$} \\
\hline $\begin{array}{c}\text { Weighted Trend } \\
(\beta)\end{array}$ & 0,90 & 0,80 & 0,70 & 0,60 & 0,50 & 0,40 & 0,30 & 0,20 & 0,10 \\
\hline 0,90 & 5780,28 & 5188,41 & 4819,41 & 4569,88 & 4337,26 & 4141,66 & 4004,59 & 3883,67 & 3819,01 \\
\hline 0,80 & 5466,51 & 4924,46 & 4635,86 & 4420,74 & 4255,27 & 4082,14 & 3916,47 & 3773,02 & 3710,49 \\
\hline 0,70 & 5181,37 & 4711,93 & 4458,43 & 4321,61 & 4202,07 & 4055,32 & 3870,07 & 3714,08 & 3645,69 \\
\hline 0,60 & 4954,92 & 4498,13 & 4254,30 & 4193,45 & 4114,30 & 3985,01 & 3816,41 & 3666,06 & 3591,50 \\
\hline 0,50 & 4773,89 & 4280,94 & 4046,13 & 4004,48 & 3951,39 & 3865,77 & 3757,17 & 3643,14 & 3577,05 \\
\hline 0,40 & 4625,67 & 4110,92 & 3850,78 & 3758,94 & 3725,62 & 3717,96 & 3648,39 & 3545,80 & 3471,67 \\
\hline 0,30 & 4459,84 & 3926,43 & 3628,81 & 3469,27 & 3461,85 & 3469,23 & 3416,84 & 3355,78 & 3289,63 \\
\hline 0,20 & 4377,30 & 3796,72 & 3443,09 & 3307,06 & 3264,97 & 3247,27 & 3210,22 & 3181,41 & 3165,99 \\
\hline 0,10 & 4363,57 & 3766,54 & 3398,64 & 3231,22 & 3142,44 & 3135,19 & 3120,23 & 3093,24 & 3117,46 \\
\hline
\end{tabular}

Table 6 - Mean Square Error (MSE)

\begin{tabular}{|c|c|c|c|c|c|c|c|c|c|}
\hline MSE & \multicolumn{7}{|c|}{ Weighted Average $(\alpha)$} \\
\hline $\begin{array}{c}\text { Weighted } \\
\text { Trend }(\beta)\end{array}$ & 0,90 & 0,80 & 0,70 & 0,60 & 0,50 & 0,40 & 0,30 & 0,20 \\
\hline 0,90 & $53.830 .846,61$ & $48.523 .183,62$ & $43.957 .323,31$ & $39.941 .988,49$ & $36.470 .605,73$ & $33.581 .611,88$ & $31.262 .087,38$ & $29.716 .772,43$ & $28.644 .443,25$ \\
\hline 0,80 & $45.278 .900,68$ & $41.323 .900,46$ & $37.628 .581,77$ & $34.024 .420,67$ & $30.602 .039,10$ & $27.565 .359,57$ & $25.066 .549,81$ & $23.395 .270,45$ & $22.241 .678,74$ \\
\hline 0,70 & $39.805 .379,96$ & $36.977 .245,36$ & $34.218 .685,07$ & $31.222 .649,68$ & $28.009 .796,18$ & $24.870 .380,44$ & $22.152 .874,65$ & $20.295 .066,54$ & $19.004 .761,43$ \\
\hline 0,60 & $35.756 .969,14$ & $33.767 .216,48$ & $31.898 .517,94$ & $29.689 .099,58$ & $26.952 .332,97$ & $23.892 .273,86$ & $21.002 .713,34$ & $18.943 .412,30$ & $17.486 .670,75$ \\
\hline 0,50 & $32.401 .579,91$ & $30.928 .660,35$ & $29.742 .884,74$ & $28.333 .727,56$ & $26.317 .854,88$ & $23.644 .694,75$ & $20.761 .238,48$ & $18.557 .483,88$ & $16.945 .800,41$ \\
\hline 0,40 & $29.526 .255,34$ & $28.290 .626,87$ & $27.489 .283,10$ & $26.666 .411,20$ & $25.387 .692,99$ & $23.370 .930,12$ & $20.791 .810,37$ & $18.589 .219,24$ & $16.870 .437,19$ \\
\hline 0,30 & $27.188 .037,17$ & $26.014 .674,47$ & $25.346 .688,01$ & $24.798 .842,98$ & $23.992 .386,31$ & $22.601 .955,32$ & $20.566 .676,07$ & $18.600 .161,90$ & $16.836 .410,76$ \\
\hline 0,20 & $25.573 .826,83$ & $24.396 .903,08$ & $23.743 .605,21$ & $23.268 .656,44$ & $22.644 .257,05$ & $21.592 .585,26$ & $20.034 .135,72$ & $18.534 .012,49$ & $16.802 .021,97$ \\
\hline 0,10 & $24.645 .305,97$ & $23.453 .843,35$ & $22.784 .973,74$ & $22.308 .364,86$ & $21.715 .598,26$ & $20.752 .214,98$ & $19.363 .767,36$ & $18.220 .401,41$ & $16.965 .815,07$ \\
\hline
\end{tabular}


Table 7 - Mean Absolute Percent Error (MAPE)

\begin{tabular}{|c|c|c|c|c|c|c|c|c|c|}
\hline MAPE & \multicolumn{9}{|c|}{ Weighted Average ( $\alpha$ ) } \\
\hline Weighted Trend $(\beta)$ & 0,90 & 0,80 & 0,70 & 0,60 & 0,50 & 0,40 & 0,30 & 0,20 & 0,10 \\
\hline 0,90 & $132,42 \%$ & $130,62 \%$ & $130,13 \%$ & $132,74 \%$ & $138,26 \%$ & $145,50 \%$ & $148,41 \%$ & $143,69 \%$ & $152,91 \%$ \\
\hline 0,80 & $128,68 \%$ & $127,28 \%$ & $127,49 \%$ & $130,19 \%$ & $135,37 \%$ & $142,45 \%$ & $145,21 \%$ & $139,85 \%$ & $149,04 \%$ \\
\hline 0,70 & $126,05 \%$ & $125,43 \%$ & $125,94 \%$ & $128,70 \%$ & $133,98 \%$ & $140,82 \%$ & $143,25 \%$ & $137,49 \%$ & $146,72 \%$ \\
\hline 0,60 & $126,20 \%$ & $125,84 \%$ & $126,95 \%$ & $130,32 \%$ & $135,75 \%$ & $142,21 \%$ & $144,15 \%$ & $139,13 \%$ & $148,03 \%$ \\
\hline 0,50 & $128,72 \%$ & $128,88 \%$ & $130,37 \%$ & $134,03 \%$ & $139,68 \%$ & $146,37 \%$ & $149,07 \%$ & $143,86 \%$ & $152,28 \%$ \\
\hline 0,40 & $133,13 \%$ & $133,49 \%$ & $135,17 \%$ & $138,98 \%$ & $145,06 \%$ & $152,63 \%$ & $155,72 \%$ & $150,30 \%$ & $158,81 \%$ \\
\hline 0,30 & $137,12 \%$ & $137,28 \%$ & $138,83 \%$ & $142,76 \%$ & $149,48 \%$ & $157,70 \%$ & $160,95 \%$ & $155,62 \%$ & $164,43 \%$ \\
\hline 0,20 & $136,68 \%$ & $136,66 \%$ & $138,11 \%$ & $142,20 \%$ & $149,44 \%$ & $157,84 \%$ & $161,41 \%$ & $156,35 \%$ & $165,32 \%$ \\
\hline 0,10 & $136,88 \%$ & $136,87 \%$ & $138,27 \%$ & $142,38 \%$ & $149,86 \%$ & $158,19 \%$ & $161,80 \%$ & $157,28 \%$ & $166,64 \%$ \\
\hline
\end{tabular}

Based on the results of forecasting errors testing using MAD, MSE, and MAPE measurements, it can be seen the optimal forecasting value for each forecasting model. The comparison of optimality between forecasting models is used to evaluate the most optimal forecasting model among other optimal forecasting models. The following are the results of forecasting comparisons based on forecasting measurement errors.

Table 8 - The Comparison of Optimality of the Forecasting Model

\begin{tabular}{|l|l|}
\hline Forecasting Model & Rank MAD \\
\hline Exponential Smoothing $(\alpha=0.10)$ & 1 \\
\hline Moving Average $(\mathrm{n}=7)$ & 2 \\
\hline Weighted Moving Average $(\mathrm{n}=7)$ & 3 \\
\hline Exponential Smoothing with Trend Adjustment $(\alpha=0.10 ; \beta=0.20)$ & 4 \\
\hline Forecasting Model & Rank MSE \\
\hline Moving Average $(\mathrm{n}=7)$ & 1 \\
\hline Exponential Smoothing $(\alpha=0.10)$ & 2 \\
\hline Weight Moving Average $(\mathrm{n}=7)$ & 3 \\
\hline Exponential Smoothing with Trend Adjustment $(\alpha=0.10 ; \beta=0.20)$ & 4 \\
\hline Forecasting Model & Rank MAPE \\
\hline Exponential Smoothing $(\alpha=0.10)$ & 1 \\
\hline Exponential Smoothing with Trend Adjustment $(\alpha=0.80 ; \beta=0.70)$ & 2 \\
\hline Weight Moving Average $(\mathrm{n}=3)$ & 3 \\
\hline Moving Average $(\mathrm{n}=3)$ & 4 \\
\hline
\end{tabular}

Table 8 present the overall ranking of forecasting model performance with different optimality measurement. Based on MAD measurement, exponential smoothing is the most optimal forecasting. Moving average was the second most optimal forecasting model, followed by weight moving average in the third and exponential smoothing with trend adjustment in the fourth. Based on MSE measurement, moving average is the most optimal forecasting model, followed by exponential smoothing in the second, weighed moving average in the third, and exponential smoothing with trend adjustment in the fourth. Based on MAPE measurement, Exponential smoothing is the most optimal forecasting model, followed by exponential smoothing with trend adjustment in the second, weighted moving average in the third, and moving average in the fourth. Since exponential smoothing was always on top rank based on MAD, MSE and MAPE, it could be a good forecasting to be applied.

The results of measurements error on time series forecasting model show that the optimality of the forecasting model depends on the amount of calculated time as explained by Heizer et al. (2017: 109) and Makridakis \& Hibon (2000). Decomposition of actual data into daily period causes data to be more fluctuated, which is why the optimality measurement value becomes large.

The selection of forecasting model should consider the cost aspect to quickly anticipate the changing demand of medical solid waste processing services for service provider for collection and treatment. Ryu and Sanchez (2003), mentions that the ease of use of forecasting models is sometimes more important than its optimality. However, the cost aspects and the ability of decision makers to use the function of forecasting are not examined in this study. Hence, the selection of forecasting is solely observed based on the level of optimality. 
The ranks optimality of the demand forecasting model for medical solid waste processing are varied, so selection of forecasting models can be determined based on the usability of optimality measurements. The optimality measurement of the MSE forecasting model is recommended to use because it shows the impact raised that must be anticipated. The MAD value is the average value of error forecasting of the demand value which is shown in the same metric unit. The MAPE value shows the percentage of error forecasting value of the actual value.

\section{CONCLUSION}

Extended data of the demand for medical solid waste processing into daily period is more effective to analyze random variation and trend but it does not good of fit for seasonal pattern. For decision maker, forecasting demand with extended data into daily period implies forecasting must be conducted every day. This forecasting is suitable to use for short-term decisions, for examples early warning system for overcapacity, supervising for job scheduling, and planning to cooperate with other medical solid waste service provider for collection and treatment.

Extended data of actual demand in daily period causes forecasting only provide information about the number of demand for one period ahead and less appropriate to forecast seasonal components. Therefore, research on the demand of medical solid waste processing services with daily data requires further research using a model that is capable of decomposing seasonal patterns.

Although the results of forecasting optimality measurements do not refer to the same forecasting model, but these result provide choices for decision makers to determine the forecasting model that will be used. The average moving forecasting model with a moving average period of 7 days could be selected to use when decision makers consider the impact of forecasting errors. Exponential smoothing forecasting models that assume stable fluctuations could be selected to use when decision makers consider forecasting errors in the same metric and percentage of forecasting errors.

\section{REFERENCES}

1. Ali, Mohammad M. \& John B. Boylan. (2011) "On the Effect Of Non-Optimal Forecasting Methods On Supply Chain Downstream Demand", IMA Journal Of Management Mathematics, 23, pp. 81-98. https://doi.org/10.1093/imaman/dpr005

2. Gusca, J., Kalnins, S. N., Blumberga, D., Bozkho, L., Khabdullina, Z., Khabdullin, A. (2015) "Assessment method of health care waste generation in Latvia and Kazakhstan", Energy Procedia 72, pp. 175-179. https://doi.org/10.1016/j.egypro.2015.06.025

3. Heizer, J., Render, B., Munson, C. (2017) "Operation Management: Sustainability and Supply Chain Management", twelfth ed., Pearson Education, Inc., United States of America.

4. Karpusenkaite, A., Ruzgas, T., Denafas, G. (2016) "Forecasting Medical Waste Generation Using Short Data Sets: Case Study Of Lithuania", Waste Management \& Research, 8(4), pp. 357-364. http://dx.doi.org/10.3846/mla.2016.951

5. Kementerian Lingkungan Hidup. (2014) "Pedoman Kriteria Teknis Pengelolaan Limbah Medis Ramah Lingkungan", Kementerian Lingkungan Hidup, Jakarta, Indonesia.

6. Komilis, D., Fouki, A., Papadopoulos, D. (2012) "Hazardous medical waste generation rates of different categories of health-care facilities', Waste Management 32, pp. 14341441. https://doi:10.1016/j.wasman.2012.02.015

7. Maamari, O., Brandam, C., Lteif, R., Salameh, D. (2015) "Health Care Waste Generation Rates and Patterns: The Case of Lebanon. Waste Management". Vol 43, September 2015, Pages 550-554. http://dx.doi.org/10.1016/j.wasman.2015.05.005.

8. Makridakis, A. Andersen, R. Carbone, R. Fildes, M. Hibon, R. Lewadowski, J. Newton, R. Winkler (1982) "The Accuracy of Extrapolation (Time Series) Methods: Results of a 
Forecasting Competitiion". Journal of Forecasting, Vol. 1, 111-153. https://doi.org/10.1002/for.3980010202

9. Makridakis, S., Wheelwright, S. C. \& Hyndman, R. J. (1998). "Forecasting methods and applications (3rd ed.)" New York: Wiley.

10. Ostertagova, Eva. \& Ostertag. (2012) "Forecasting using Smiple Simple Exponetial Smoothing Method". Acta Electronica et Informatica, Vol 12, No. 3, 2012. https://doi.org/10.2478/v10198-012-0034-2

11. Ryu, Kisang. \& Alfonso Sanchez (2003). The Evaluation of Forecasting Methods at an Institutional Foodservice Dining Facility. Journal of Hospitality Financial Management. Vol. 11: Iss, Article 4. https://doi.org/10.1080/10913211.2003.10653769

12. Stevenson, William J. (2015). Operation Management, Twelfth Edition. New York: McGraw-Hill Education.

\section{APPENDIX}

Appendix A - Moving Average

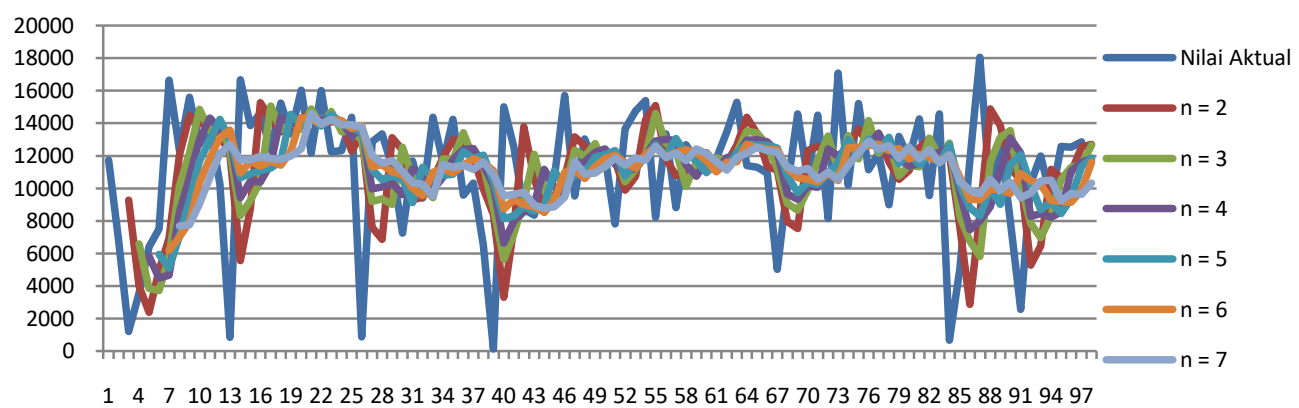

Appendix B - Weighted Moving Average

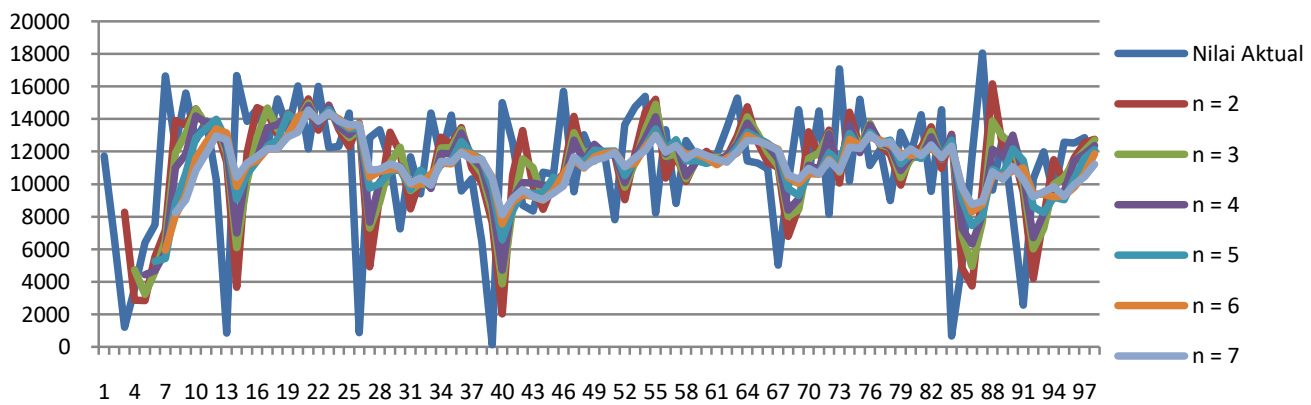

Appendix C - Exponential Smoothing

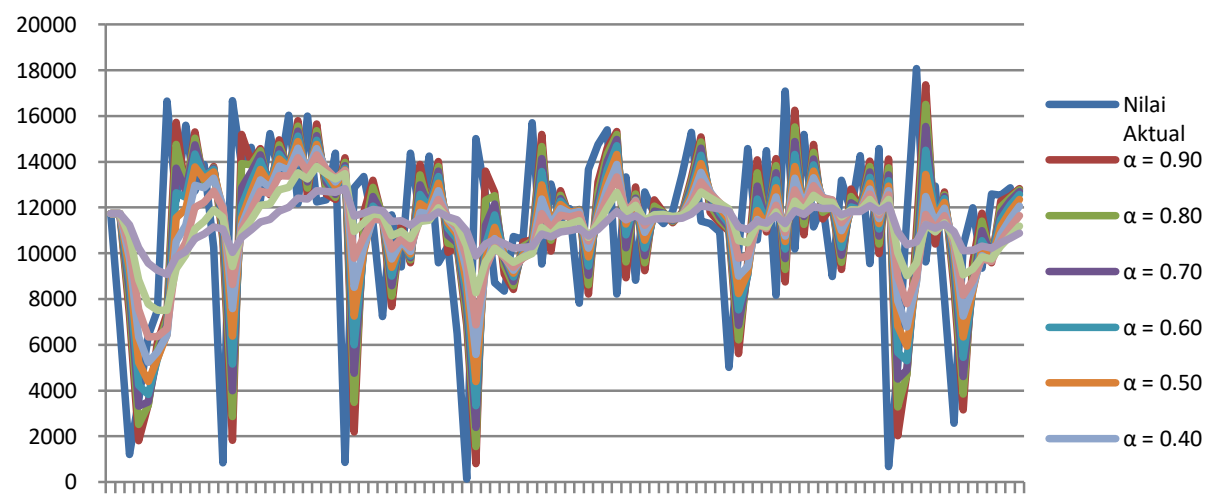

15913172125293337414549535761656973778185899397 
Appendix D - Exponential Smoothing with Trend Adjustment $\alpha=0.90$
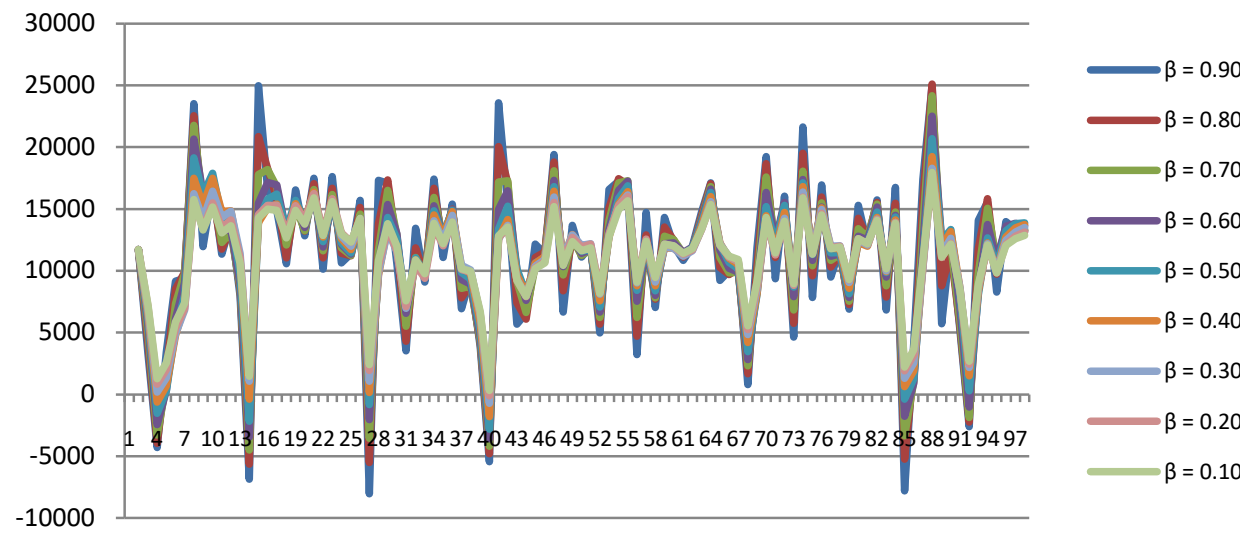

Exponential Smoothing with Trend Adjustment $\alpha=0.80$
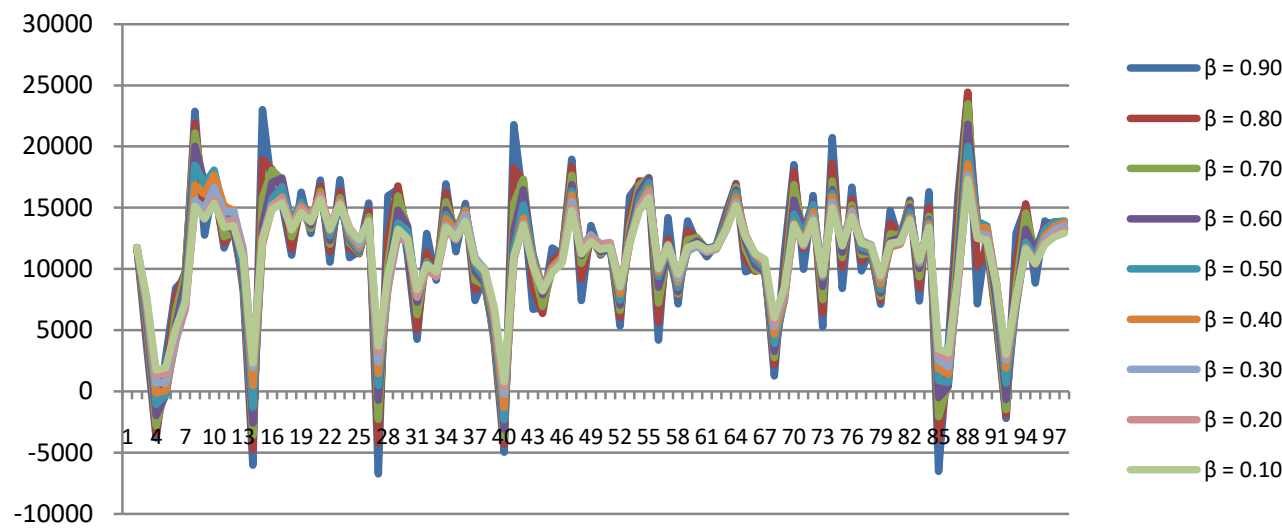

Exponential Smoothing with Trend Adjustment $\alpha=0.70$
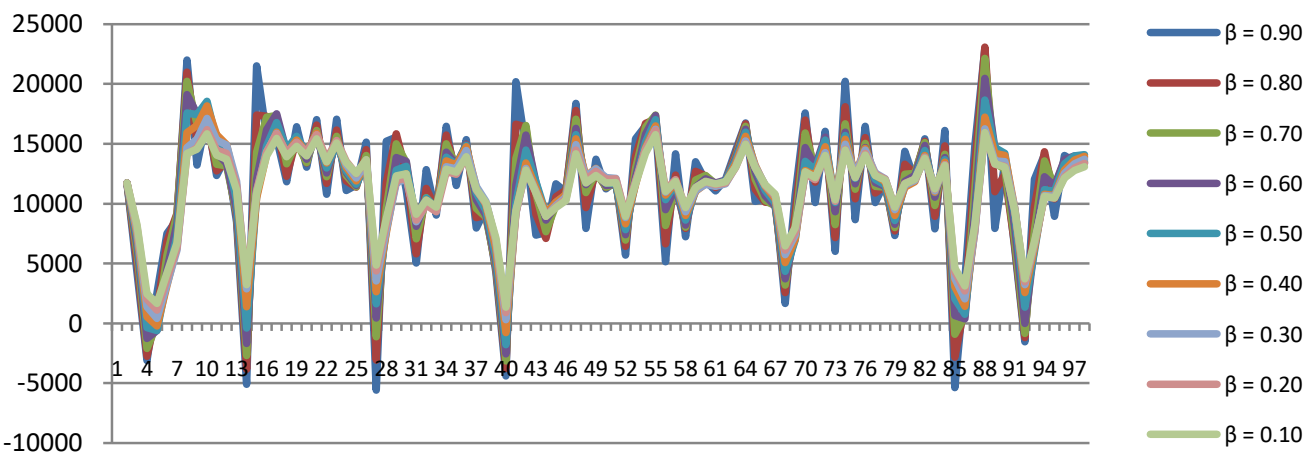

Exponential Smoothing with Trend Adjustment $\alpha=0.60$
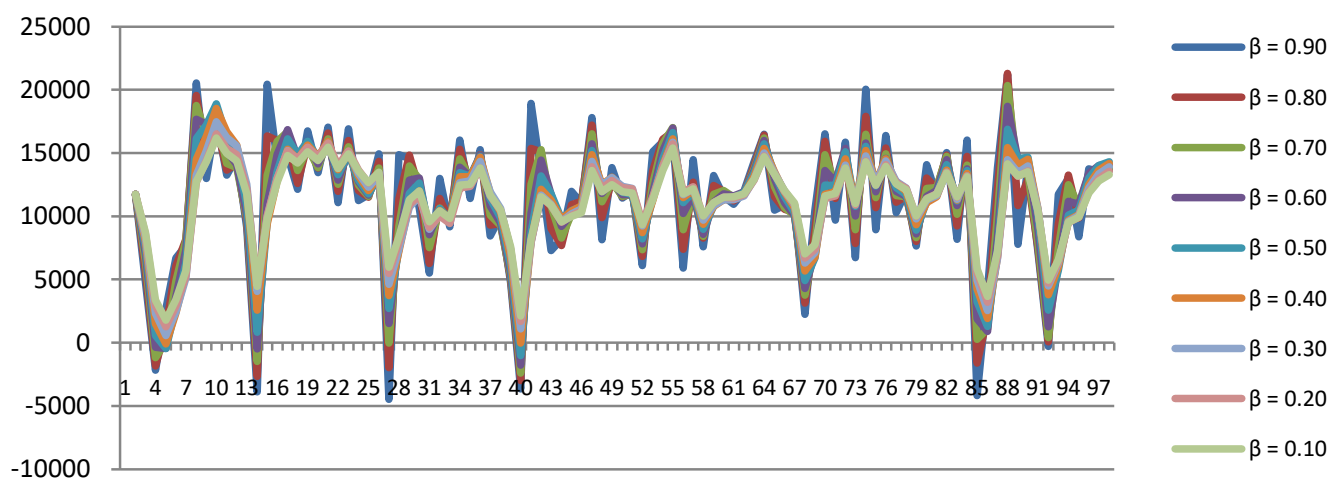
Exponential Smoothing with Trend Adjustment $\alpha=0.50$
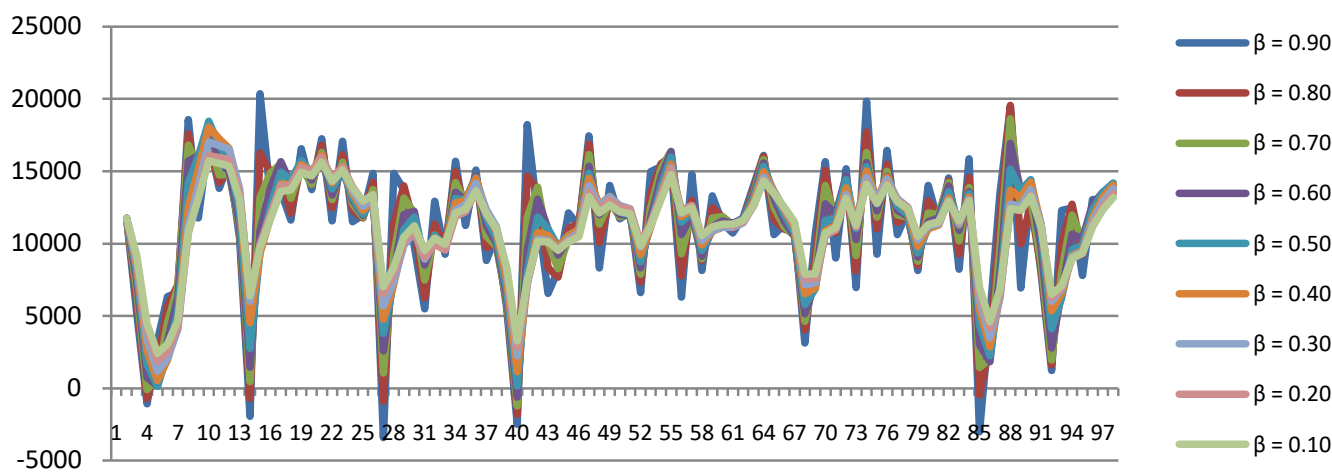

Exponential Smoothing with Trend Adjustment $\alpha=0.40$
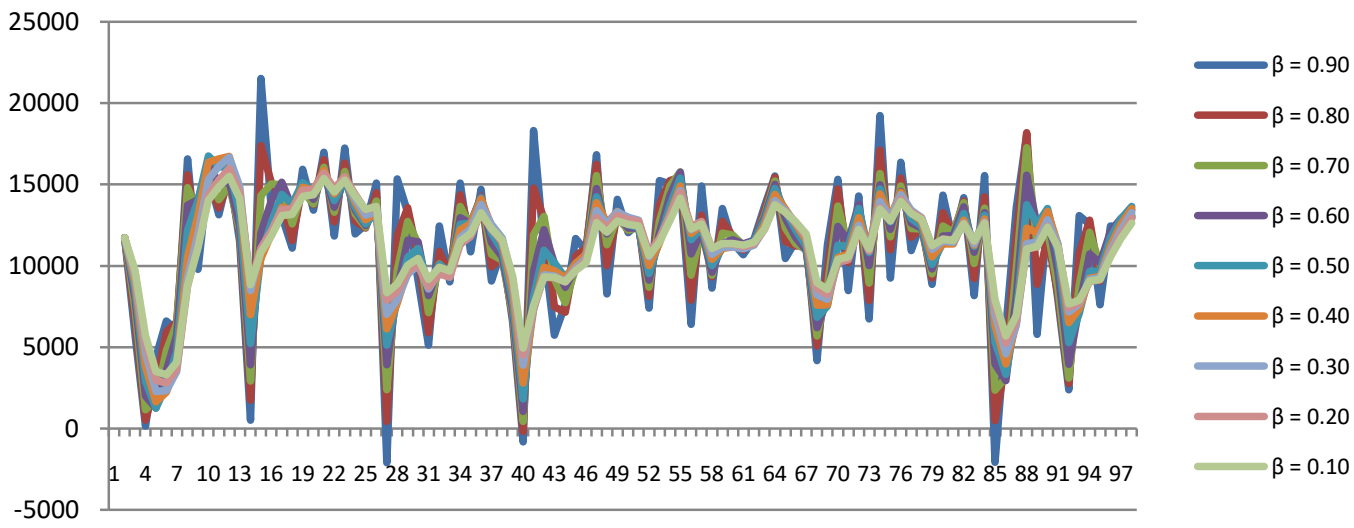

Exponential Smoothing with Trend Adjustment $\alpha=0.30$
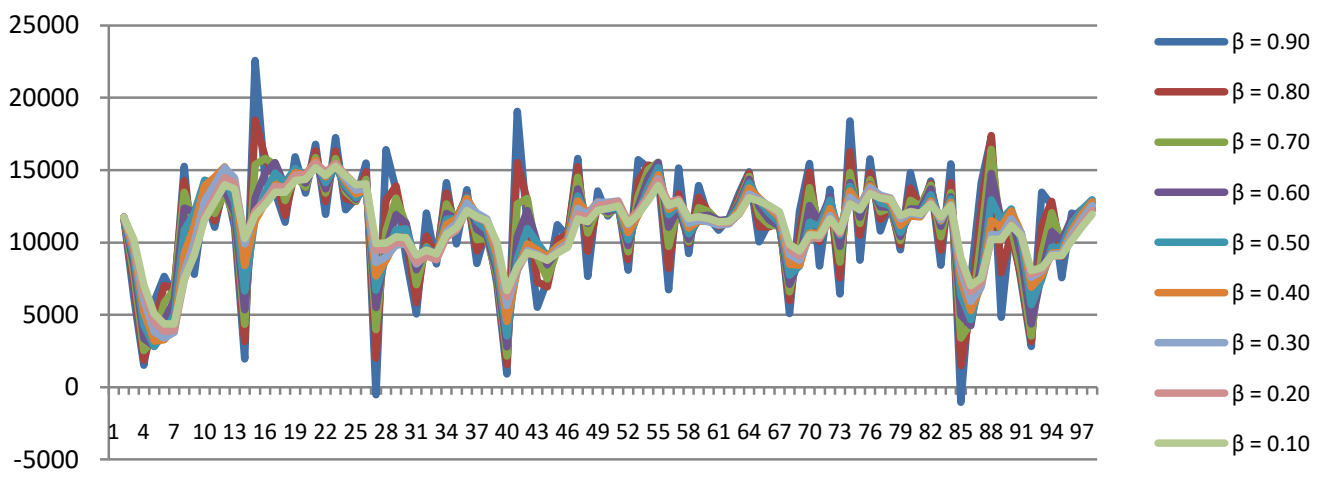

Exponential Smoothing with Trend Adjustment $\alpha=0.20$
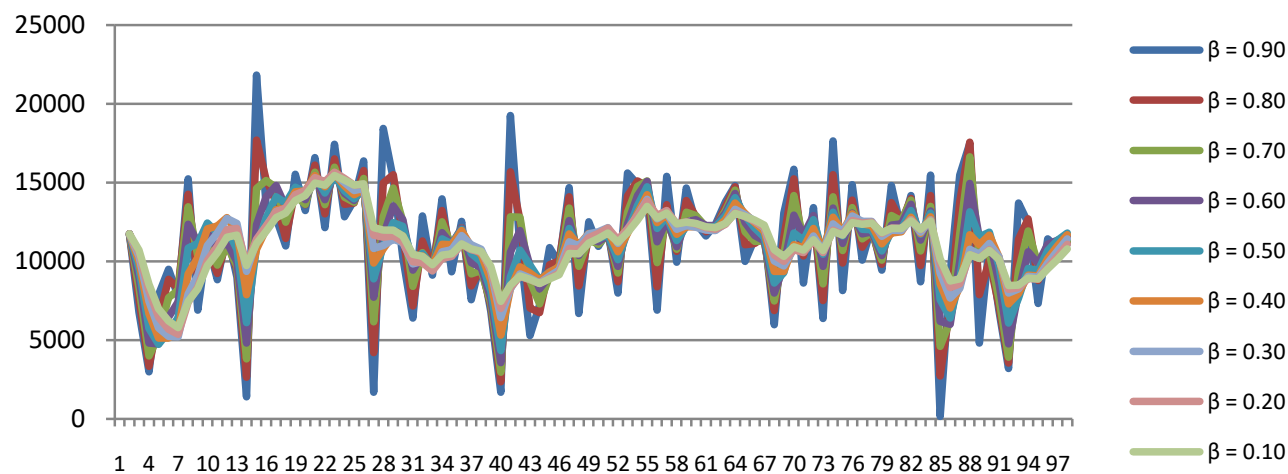
RJOAS, 11(95), November 2019

Exponential Smoothing with Trend Adjustment $\alpha=0.10$

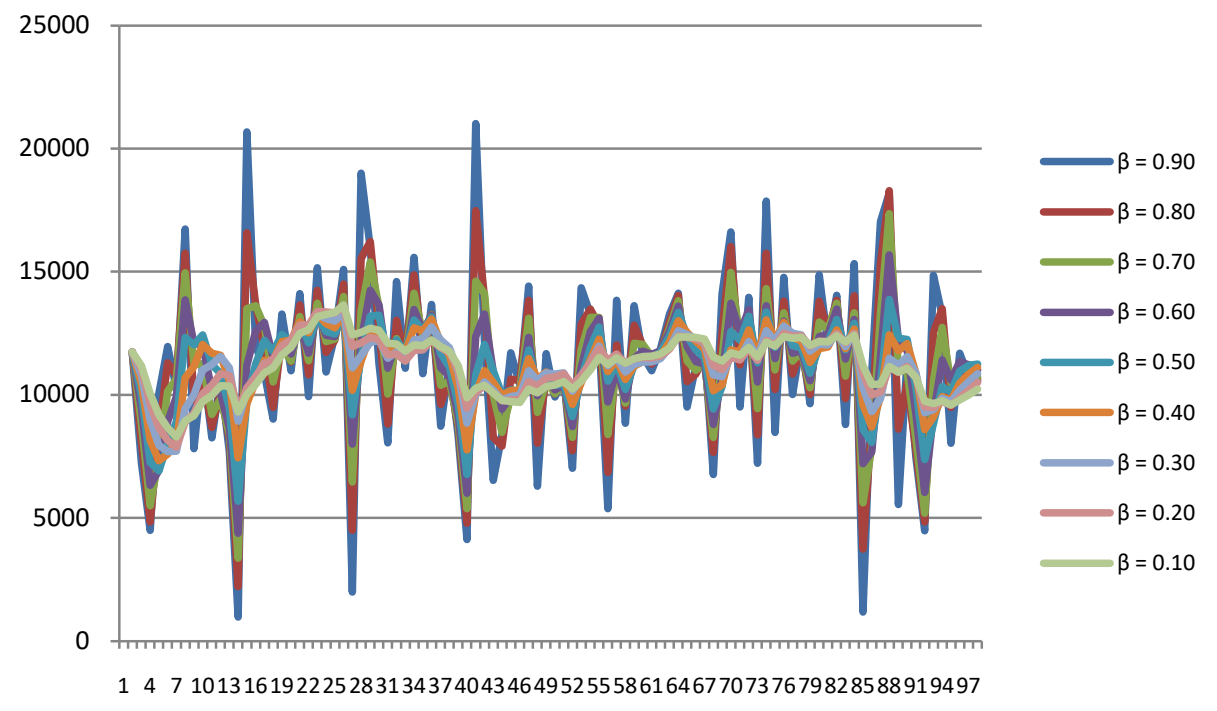

